\title{
Bir çocuk hastada Chilaiditi Sendromu: vaka sunumu
}

\section{Chilaiditi Syndrome in a child patient: a case report}

\section{Sabri DEMIR ${ }^{\text {1a }}$, Emrah ŞENEL²}

\author{
${ }^{1}$ Bartın Devlet Hastanesi, Çocuk Cerrahi Kliniği, Bartın, \\ ${ }^{2}$ Yıldırım Beyazıt Üniversitesi Tıp Fakültesi, Çocuk Cerrahi Kliniği, Ankara, TÜRKiYE
}

\section{ÖZET}

Chilaiditi sendromu tekrarlayan karın ağrısı, solunum sıkıntısı, kabızlık ve kusma ile karakterize, nadir görülen bir hastalıktır. Genelde asemptomatik olarak görülür ve tesadüfen çekilen karın veya akciğer grafileri ile teşhis konur. Grafilerde karaciğer sağ lobu ile diyafram arasına kolon veya ince barsak segmentinin interpoze olduğu görülür. Asemptomatik olgularda tedaviye gerek yoktur. Semptomatik hastalarda ise ilk tedavi konservatiftir. Obstrüksiyon, kolonik volvulus veya perforasyon saptanan hastalarda ise cerrahi tedavi yapılmalıdır. Özellikle çocuk hastalarda nadir görülen bir sendrom olması nedeniyle kronik karın ağrısı, kusma ve karında şişlik ve öksürük şikayeti ile getirilen ve Chilaiditi sendromu tanısı koyduğumuz 8 yaşında kız hastayı sunmayı amaçladık.

Anahtar kelimeler: Chilaiditi sendromu, çocuklar, karın ağrısı, kolopeksi.

\section{ABSTRACT}

Chilaiditi syndrome is a rare disease which is characterized by recurrent abdominal pain, respiratory distress, constipation, and vomiting. It is usually asymptomatic, and the anomaly is diagnosed incidentally on chest or abdominal radiographs. The radiographs show interposed segment of colon or small bowel between the right lobe of the liver and the diaphragm. Treatment is not required for asymptomatic cases. In symptomatic patients, the initial treatment is conservative. Surgical treatment is performed in patients with obstruction, colonic volvulus or perforation. Beeing a rare syndrome in pediatric patients, we aimed to present an 8 year old female patient diagnosed as Chilaiditi syndrome, who has chronic abdominal pain, vomiting, and cough.

Key words: Chilaiditi syndrome, children, abdominal pain, colopexy.

Sorumlu Yazar a: Sabri DEMiR, MD. Bartın Devlet Hastanesi, Çocuk Cerrahisi Kliniği,

Bartın, TURKEY

Phone: 00905324761943 e-mail: drsabridemir@gmail.com

Received: 02.08.2015 Accepted: 30.08.2015

doi: $10.18663 /$ tjcl.46222 


\section{Giriş}

Chilaiditi sendromu nadir görülen bir konjenital anomalidir. Özellikle çocuk hastalarda daha az bildirilmiştir. Anatomik olarak barsak segmentlerinin hepatodiafragmatik bölgeye interpozisyonu olarak tanımlanır. Hem ince barsaklar düzeyinde hem de kalın barsaklar düzeyinde interpozisyon olabilir. Genelde asemptomatik radyolojik bir bulgu olarak görülmekle birlikte karın ağrısı, bulantı, kusma ve solunum sıkıntısıyla da ortaya çıkabilir. İlk defa 1910 yılında Viyana'lı bir radyolog olan Demetrius Chilaiditi tarafından üç asemptomatik olguda bildirilmiştir [1].

Chiliaditi sendromunun özellikle çocuk hastalarda nadir görülmesi nedeniyle bir olgumuzu literatür eşliğinde sunmayı amaçladık.

\section{Olgu Sunumu}

Olgumuz, yaklaşık 5 aydır tekrarlayan karın ağrısı, karında şişkinlik ve kusma şikayetleri olan 8 yaşında kız hastaydı. Son iki ayda öksürük şikayetleri de tabloya eklenmişti. Hastanın fizik muayenesinde, palpasyon ile epigastrik ve sağ üst kadranda hafif ağrı vardı. Akciğer sesleri ve diğer sistem muayene bulguları doğal idi. Kan tetkiklerinde; beyaz küre 10.800, hemoglobin $12,7 \mathrm{~g} / \mathrm{dL}$, hematokrit \%37,0, trombosit 256.000, sodyum 137 $\mathrm{mmol} / \mathrm{L}$, potasyum 4,39 mmol/L idi. Ayakta direk batın grafisi ve ön-arka akciğer grafilerinde; sağda, diyafram ve karaciğer arasında hava gölgesi tespit edildi (Resim 1). Diyafram hernisi ön tanısı ile çekilen üst abdomen ve toraks tomografilerinde; sağ taraftaki diyaframın yukarı doğru eleve olduğu ve kolonik haustra görüntüsünün karaciğer ile diyafram arasında olduğu görüldü. Hastaya Chilaiditi sendromu teşhisi kondu (Resim 2). Hastaya bol lifli diyet ve medikal tedavi (boşaltıcı lavmanlar ve laktüloz içeren şurup) başlandı. Bir ay takip edilen hastanın semptomlarında azalma olmakla birlikte, ailesinin isteği üzerine üçüncü basamak hastaneye ileri tetkik ve tedavi amacıyla sevk edildi ve çekilen baryumlu kolon grafisinde, hepatik fleksura'nın sağ karaciğer lobu ile diyafram arasına yer değiştirip girdiği gözlendi (Resim 3). Hastanın tanısı bu merkezde de doğrulandıktan sonra takip için hastanemize geri getirildi.

Hasta 8 ay diyet önerileri (bol lifli diyet) ve medikal tedavi ile takip edildi. Şikayetleri büyük oranda azalan hasta halen tarafımızdan takip edilmektedir.

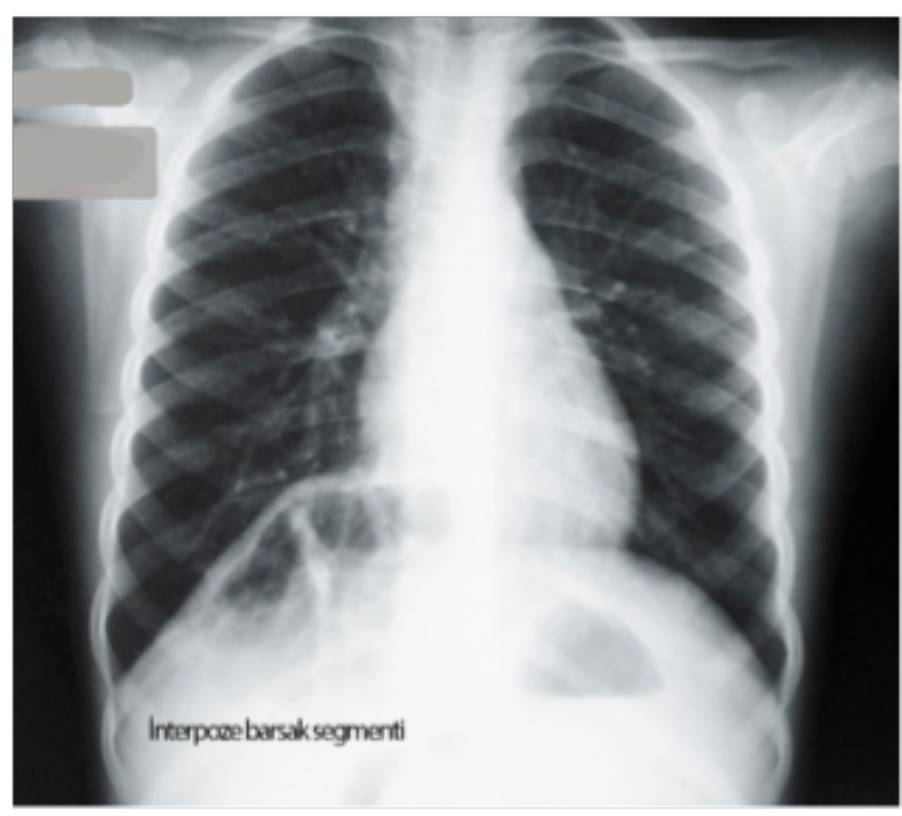

Resim 1. Akciğer grafisinde sağ karaciğer lobu ve diyafram arasına interpoze olmuş hepatik fleksura segmenti görülmektedir.

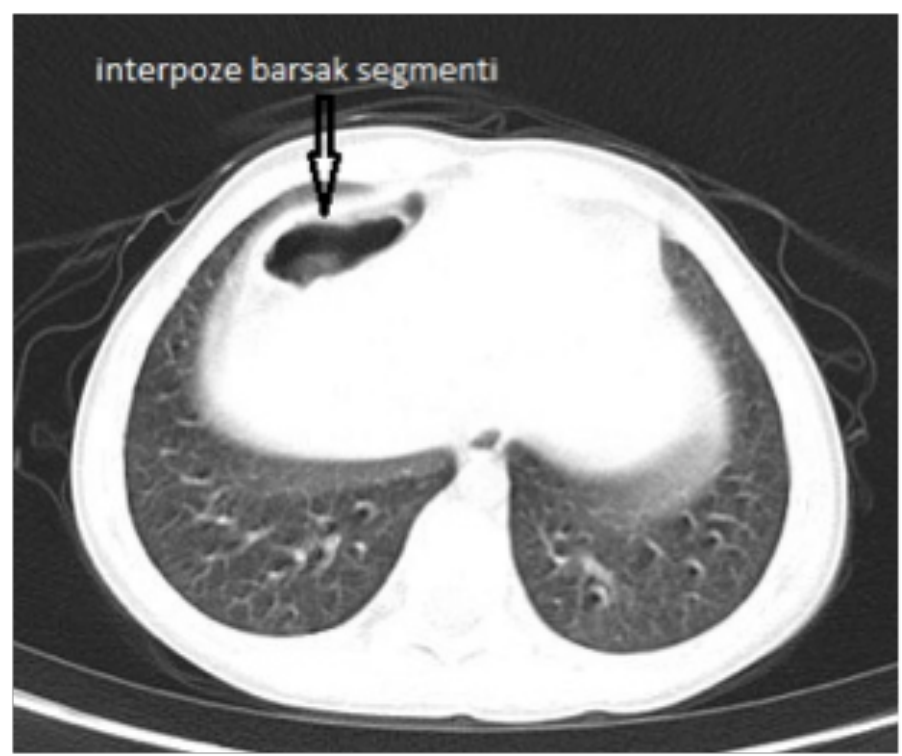

Resim 2. Toraks tomografisinde sağ karaciğer lobu ve diyafram arasına interpoze olmuş hepatik fleksura segmenti görülmektedir. 


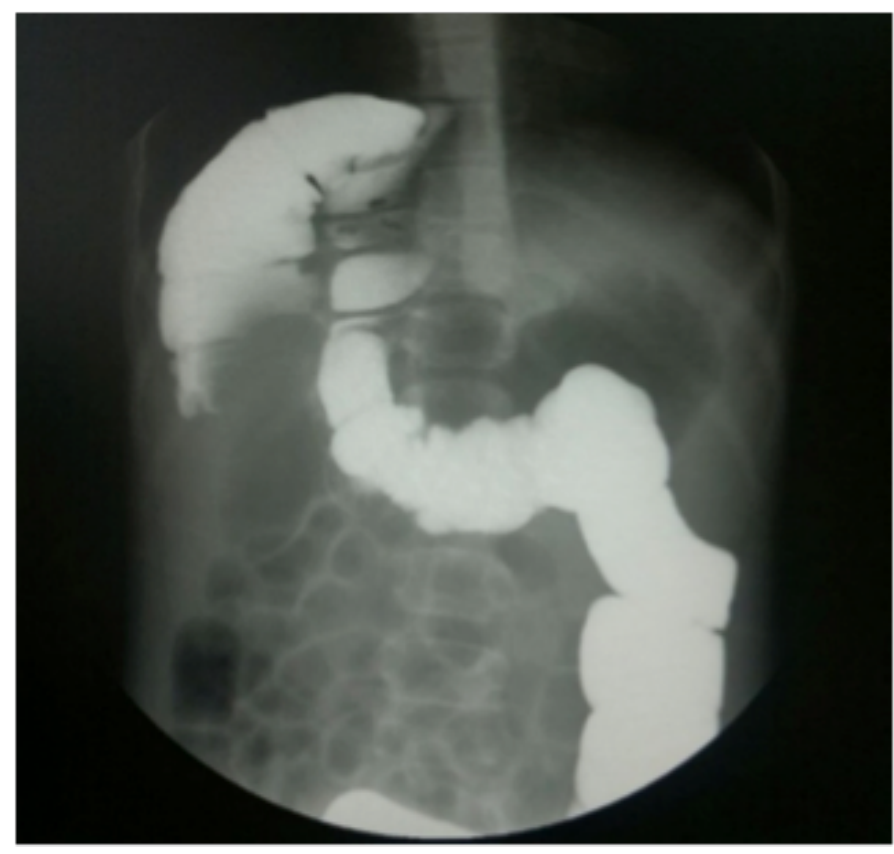

Resim 3. Baryumlu kolon grafisinde sağ karaciğer lobu ve diyafram arasına interpoze olmuş hepatik fleksura segmenti görülmektedir.

\section{Tartışma}

Chilaiditi sendromu anatomik bir anomali olarak kolon veya ince barsağın, hepatodiyafragmatik alana interpoze olması sonucu meydana gelir. Nadiren görülür ve genellikle asemptomatik seyreder [2]. Bir radyoloji uzmanı olan Demetrius [1] 1910 yılında, üç asemptomatik olguda, karaciğer ve diyafram arasına kolonun interpoze olduğunu tesadüfen saptamıştır Sonradan bu görünüm Chilaiditi bulgusu olarak isimlendirilmiştir. Klinik semptomların da eşlik ettiği olgularda ise Chiliaditi sendromu olarak adlandırılır [3,4]. İnsidansı \%0,025-0,28 arasında değişir [5]. Radyolojik incelemeler esnasında, tesadüfen saptanır. Literatürde bildirilmiş çocuk hasta sayısı azdır. İnsidansı yaşla artar ve erkek/kadın oranı 4/1'dir. Çoğunlukla asemptomatik kalmakla birlikte, hafif karın ağrısından, intermittan barsak obstrüksiyonuna kadar bir dizi semptom oluşturabilirler [2].

Bu sendromun oluşmasında, karaciğer pitozisi, küçük karaciğer karaciğerin asıcı bağlarının relaksasyonu gibi karaciğer ile ilgili faktörler; diyafram kaslarında zayıflama ve dejenerasyon, frenik sinir paralizisi, tüberküloz ve amfizeme bağlı intratorasik basınçta değişikliklere neden olan diyafragmatik faktörler; megakolon, konjenital nedenlerle kolonun anormal mobilizasyonu, mezenter gevşekliği ile aşırı ölçüde barsak motilitesi,çekal fiksasyon yetersizliği, intraabdominal basınç gradientinin artması (gebelik) gibi intestinal faktörler; travma ve buna bağlı oluşan yapışıklıklar ve aşırı hava yutma ve buna bağlı distansiyon gelişimi gibi faktörler sorumlu tutulmuştur [6].

Olguların çoğu asemptomatiktir. Klinik olarak en yaygın semp- tomlar bulantı, kusma, iştahsızlık, kabızlık, karında şişkinlik ve sağ üst kadran veya epigastrik ağrıdır. Daha az olmak üzere nefes darlığı, kalpte aritmi, akut intestinal obstrüksiyon ve kolonun volvulusu gibi ciddi komplikasyonlar ile birlikte olabilir [2] . Bizim olgumuzda karın ağrısı, şişkinlik, kusma ve öksürük bulguları mevcuttu.

Radyolojik bulgulara göre Chilaiditi bulgusu tanısı koymak için 3 kriter mutlaka olmalıdır. Bunlar; sağ hemidiyafram araya giren barsak segmentleri tarafından karaciğerin üzerinden yukarı doğru eleve edilmiş olması, barsak segmentinin içi hava ile şişirilmiş olması (pseudopneumoperitoneum) ve karaciğerin üst kenarı sol hemidiyaframın seviyesinin altına itilmiş olmasıdır [7].

Chilaiditi sendromunun ayırıcı tanısında pnömoperitoneum ve subfrenik abse düşünülmelidir. Diyafram altında kolona ait normal "plicae circulares" veya haustral görünümlerinin olması Chilaiditi bulgusu ile bu hastalıkların ayırıcı tanısında yardımcı olur. Chiliaditi bulgusu olan hastalarda pozisyonun değiştirilmesi ile batın içinde serbest hava olan hastaların aksine gaz gölgesi yer değiştirmez. Benzer şekilde, ultrason ile bakılırken pnömoperitoneumu olan hastaların aksine, Chiliaditi bulgusu olan hastaların pozisyonunun değiştirilmesi ile gaz ekosunun yeri değişmez [8]. Subdiyafragmatik havanın perforasyona bağlı serbest havaya ait görünüm mü, yoksa Chilaiditi bulgusu/sendromuna ait barsak içindeki hava mı olduğunun, röntgen ve ultrasonografi ile ayırt edilemediği olgularda ayırıcı tanı için bilgisayarlı tomografi çekilebilir. Baryumlu kolon grafisi çekilerek, interpoze barsak segmentinin kolona mı, ince barsaklara mı ait olduğu ayırt edilebilir. Ayırıcı tanısında barsak obstrüksiyonu, volvulus, invaginasyon, iskemik barsak, apandisit ve divertikülit de unutulmamalıdır. Ancak nadir olarak bu hastalıklar Chilaiditi bulgusu ile birlikte görülebilir [2].

Chilaiditi sendromu, hem ince barsaklar düzeyinde hem de kalın barsaklar düzeyinde intestinal obstrüksiyonun çok nadir nedeni olabilir $[9,10]$. Aynı zamanda Chilaiditi sendromlu hastalarda kolonik psödo-obstrüksiyon (Ogilvie sendromu) görülmüştür [11]. Ek olarak Chilaiditi sendromu bazı pulmoner ve kolon, rektum veya mide gibi gastrointestinal malignansiler ile birlikte görülebilir [12-14]. Chilaiditi sendromu başlangıçta diyafram hernisi ile karıştırılabilir [15-17]. Nitekim bizim olguda da önce diyafram hernisi düşünüldü. Ayırıcı tanı baryumlu kolon grafisi ve/veya tomografi çekilerek konabilir. İlginç olarak, sağ Bochdalek hernisi ile barsak interpozisyonu birlikteliği olguları bildirilmiştir $[15,16]$.

Chilaiditi sendromunun tedavisinde önce yatak tedavisi, intravenöz mayii verilerek sıvı replasmanı, barsak dekompresyonu, enema, laksatifler ve diyet önerileri ile başlanmalıdır. Tedavinin takibinde tekrarlayan röntgen çekimleri ile diyafram altındaki havanın azaldığı gösterilebilir. Ancak konservatif tedaviye yanıt vermeyen bazı hastalarda cerrahi müdahale yapılır. Obstrüksiyon, kolonik volvulus veya perforasyon saptanan hastalarda ise 
cerrahi tedavi yapılmalıdır. Literatürde bildirilen yetişkin serilerinde son zamanlarda uzun süren tekrarlayıcı karın ağrısı şikayeti olan hastalarda da cerrahi tedavi yapıldığı bu yüzden cerrahi tedavi yapılan hasta sayısında artış olduğu görülmektedir. Cerrahi tedavide ise, kolon rezeksiyonu, kolopeksi ve hepatopeksi yapılır. Son zamanlarda bu sendromun cerrahi tedavisinde minimal invazif cerrahi yöntemler de kullanılmaya başlanmıştır [6].

Sonuç olarak, Chilaiditi sendromu nadir görülen ve genelde asemptomatik olarak görülen bir antite olmasına rağmen, tekrarlayan karın ağrısı ve/veya solunum semptomları ile gelen hastalarda ayırıcı tanıda düşünülmelidir. Bu olgularda görüntüleme yöntemleri ile ayırıcı tanıya gidilmelidir.

\section{Çıkar çatışması ve Finansman Beyanı}

Bu çalışmada çıkar çatışması ve finansman destek alındığı beyan edilmemiştir.

\section{Kaynaklar}

1. Chilaiditi D. Zur frage der hepatoptose und ptose im allgemeinen im anschluss an drei fälle von temporärer, partieller leberverlagerung. Fortschritte auf dem Gebiete der Röntgenstrahlen. 1910; 16: 173-208.

2. Moaven O, Richard A. Hodin R.A. Chilaiditi syndrome: a rare entity with important differential diagnoses. Gastroenterology and Hepatology 2012; 8. 276-8.

3. Plorde JJ, Raker EJ.Transverse colon volvulus and associated Chilaiditi's syndrome:case report and literature review. Am J Gastroenterol 1996; 91: 2613-6.

4. Çağlayan K, Doğan H, Çelik A. Chiliaditi Sendromu: iki olgu sunumu. Bakırköy Tıp Dergisi, 2010; 6: 78-80.

5. Orangio GR, Fazio VW, Winkelman E, Mc Gonagle BA. The Chilaiditi syndrome and associated volvulus of the transverse colon: an indication for surgical therapy.Dis Colon Rectum 1986; 29: 653-6.

6. Blevins WA, Cafasso DE, Fernandez M, Edwards MJ. Minimally invasive colopexy for pediatric Chilaiditi syndrome. J Ped Surg 2011; 46; e33-e35.
7. Lekkas CN, Lentino W. Symptom-producing interposition of the colon. Clinical syndrome in mentally deficient adults. JAMA. 1978; 240: 747-50.

8. Sato $\mathrm{M}$, Ishida $\mathrm{H}$, Konno $\mathrm{K}$, et al. Chilaiditi syndrome: sonographic findings.Abdom Imaging. 2000; 25: 397-9.

9. Antonacci N, Di Saverio S, Biscardi A, Giorgini E, Villani S, Tugnoli G. Dyspnea and large bowel obstruction: a misleading Chilaiditi syndrome. Am J Surg.2011; 202: e45-e47.

10. Mateo de Acosta Andino DA, Aberle CM, Ragauskaite L, et al. Chilaiditi syndrome complicated by a closed-loop small bowel obstruction. Gastroenterol Hepatol (NY) 2012; 8: 274-6.

11. Suárez-Grau JM, Cháves $\mathrm{CR}$, Bernal FL, Ciuró FP. Colonic pseudo-colonic obstruction (Ogilvie syndrome) in a patient with Chilaiditi syndrome. Cir Esp 2011; 89: e2.

12. Melester T, Burt ME. Chilaiditi's syndrome. Report of three cases. JAMA 1985; 254: 944-5.

13. Yagnik VD. Chilaiditi syndrome with carcinoma rectum: rare entity. Saudi J Gastroenterol 2011; 17: 85-6.

14. Sendon JL. Primary lung cancer and the Chilaiditi syndrome. Chest 1975; 67: 130.

15. Kamiyoshihara M, Ibe T, Takeyoshi I. Chilaiditi's sign mimicking a traumatic diaphragmatic hernia. Ann Thorac Surg 2009; 87: 959-61.

16. Schneidau A, Baron HJ, Rosin RD. Morgagni revisited: a case of intermittent chest pain. Br J Radiol 1982; 55: 238-40.

17. Vallee PA. Symptomatic morgagni hernia misdiagnosed as Chilaiditi syndrome. West J Emerg Med 2011; 12: 121-3. 